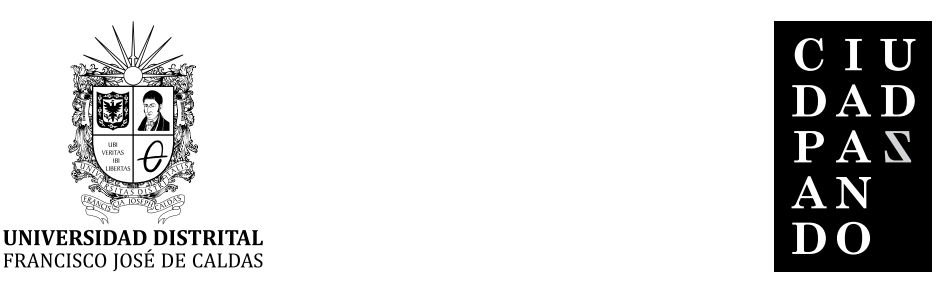

\title{
DOSSIER
}

Artículo de investigación científica

\section{Memorias de una abuela sobre Plaza de mayo: la historia de Ledda y su familia en la militancia, la dictadura y las luchas por la justicia ${ }^{1}$}

Memories of a grandmother of Plaza de mayo: the story of Ledda and his family in militancy, dictatorship, and their struggles for justice

Memórias de uma avó da Plaza de mayo: a história de Ledda e sua família em militância, ditadura e lutas pela justiça

\section{Miriam Kriger $^{2}$}

\section{Luciana Guglielmo ${ }^{3}$}

Para citar este artículo: Kriger, M. y Guglielmo, L. (2017). Memorias de una abuela sobre Plaza de mayo: la historia de Ledda y su familia en la militancia, la dictadura y las luchas por la justicia. Revista Ciudad Paz-ando, 10(2), 19-28.

doi: https://doi.org/10.14483/2422278X.12769

Fecha de recepción: 24 de noviembre de 2017

Fecha de aprobación: 08 de febrero de 2018

\footnotetext{
1 Este artículo se realiza en el marco del proyecto de la Unidad Ejecutora CIS-IDES CONICET (PUE 22920160100005CO), del programa de investigación: subjetividades políticas juveniles en contextos nacionales contemporáneos, dirigido por la doctora Miriam Kriger en CIS-IDES CONICET, y la investigación que presenta se vincula a la investigación doctoral de Luciana Guglielmo, con dirección de la doctora Miriam Kriger en la Facultad de Periodismo y Comunicación Social.

2 Doctora en Ciencias Sociales (FLACSO), investigadora adjunta del Consejo Nacional de Investigaciones Científicas y Técnicas (CONICET) con sede en el CIS/IDES. Docente investigadora de la Universidad de Buenos Aires. Correo electrónico: mkriger@gmail.com

3 Estudiante de Doctorado en el Programa de la Facultad de Periodismo y Comunicación Social de la Universidad de La Plata (FPyCS, UNLP). Correo electrónico: lucianaguglielmo@yahoo.com.ar
} 


\section{RESUMEN}

Este artículo presenta hallazgos de una investigación sobre memorias de abuelas de Plaza de mayo, tomando el caso de "Ledda" Barreiro, referente de la filial Mar del Plata, cuya hija fue secuestrada y desaparecida en 1976, y su nieto/a aún no fue encontrado/a. Se le realizó una entrevista en profundidad, estableciendo los siguientes ejes: (a) la militancia política (1975-1983); (b) la desaparición de Silvia y su duelo (1976 en adelante) y (c) el testimonio ante la justicia (2010 y 2012). Se espera contribuir a problematizar e historizar los regímenes de memoria sobre el pasado reciente en Argentina, con foco en las víctimas del terrorismo de Estado durante la dictadura cívico militar (1976-1983).

Palabras clave: abuelas de Plaza de mayo, construcción de memorias, militancia política, narrativas biográficas.

\section{ABSTRACT}

This article presents findings of an investigation into memories of grandmothers of Plaza de mayo, taking the case of "Ledda" Barreiro, a reference of the subsidiary Mar del Plata, whose daughter was kidnapped and disappeared in 1976, and her grandson was not yet found -We conducted an in-depth interview, establishing the following axes: a) political militancy (1975-83); b) the disappearance of Silvia and her grief (1976 onwards) and c) the testimony before the courts (2010 and 2012). We hope to contribute to problematize and historicize the regimes of memory about the recent past in Argentina, with a focus on the victims of state terrorism during the civil-military dictatorship (1976-1983).

Keywords: abuelas de Plaza de mayo, biographic narratives, construction of memories, political militancy.
Este artigo apresenta as descobertas de uma investigação sobre as memórias das avós da Plaza de mayo, levando o caso de "Ledda" Barreiro, uma referência da filial Mar del Plata, cuja filha foi seqüestrada e desapareceu em 1976 e seu neto ainda não estava encontrado Realizamos uma entrevista aprofundada, estabelecendo os seguintes eixos: a) militância política (1975-83); b) o desaparecimento de Silvia e seu sofrimento (1976 em diante) e c) o testemunho perante os tribunais (2010 e 2012). A chave da análise está ligada ao caráter dinâmico que atribuímos aos processos de construção de memórias condensadas nesses eixos que, no caso estudado, têm um desenvolvimento ininterrupto de quatro décadas. Em toda parte, entrelaçam na subjetividade do entrevistado e são articulados com outros processos de construção intersubjetivos: institucionais e sociais. Esperamos contribuir para problematizar e historizar os regimes de memória sobre o passado recente na Argentina, com foco nas vítimas do terrorismo de estado durante a ditadura civil-militar (1976-1983).

Palavras-chave: abuelas de Plaza de mayo, construção de memorias, militaria política, narratividades biográficas. 


\section{Presentación}

Con este artículo se pretende contribuir a la comprensión de los procesos de construcción de las memorias familiares de los desaparecidos (Calveiro, 1998; Crenzel, 2010) por el terrorismo de Estado en la última dictadura cívico-militar en Argentina, en continuidad con trabajos previos (Guglielmo y Kriger, 2011; 2012; 2014; 2015) y estableciendo relaciones con una investigación doctoral en curso. ${ }^{4}$ Particularmente, interesa aquí acceder a la dimensión subjetiva de tales procesos desde una perspectiva biográfica, por lo cual se ahondarás en analizar específcamente la historia familiar de una mujer militante y a la vez madre de una hija desaparecida y abuela en búsqueda de su nieto/a, vale decir, una protagonista con extraordinaria trayectoria política, hasta la actualidad.

Se trata de Ledda, cuya narrativa biográfica nos permite comprender rasgos específicos de la militancia de los 70 , ampliamente estudiada por diversos autores en las últimas décadas (Anguita y Caparrós, 2006; Calveiro, 2005; Carnovale, 2011; 2013; 2014; 2015; Ollier, 1986; 2009; Terán ,2006), y en este caso con la peculiaridad de que se ahondará en lo familiar en primer término, considerando asimismo la condición materna y femenina de la entrevistada. Adicionalmente, se trata de una abuela de Mar del Plata, donde la violencia política y el terrorismo de Estado —antes y después del golpe - han tenido características propias, cuya descripción supera el marco de este trabajo.

Se procurará demostrar el modo en que la política puede configurarse como camino de vida y su peculiar relación con la muerte en el contexto estudiado, el cual genera la permanente necesidad de construir estrategias de supervivencia y de duelo. Se analizará en el caso de Ledda, cómo se componen las complicidades y códigos que entraman de un modo peculiar las relaciones entre compañeros militantes y familiares, incluyendo a su hija desaparecida; finalmente, se hará énfasis en sus luchas por la justicia, en su testimonio en años recientes en los juicios a agentes directos del terrorismo de Estado y de crímenes de lesa humanidad, tras la derogación de las leyes del olvido. ${ }^{5}$

\section{El estudio}

En este trabajo se analizará una entrevista en profundidad a la abuela Ledda realizada en octubre de 2015 en la sede de Mar del Plata de Abuelas de Plaza de Mayo. El tiempo de la entrevista fue de cuatro horas veinte minu-

4 Tesis doctoral de Luciana Guglielmo en el Programa de Doctorado de la Facultad de Periodismo y Comunicación Social de la Universidad Nacional de La Plata (FPyCS, UNLP), dirigida por la doctora Miriam Kriger.

5 En el 2005 se derogaron las "leyes del perdón y de la impunidad" en el 2005, cuya inconstitucionalidad quedó decretada en virtud de no prescripción de los crímenes de lesa humanidad, lo que permitió que cientos de represores, civiles y militares, sean juzgados. tos, sin pausas; fueron registradas en audio, con apoyo de transcripciones y observaciones por escrito. La actitud general y la disposición de Ledda para contar su historia fueron muy positivas, lo cual suele suceder en general con las abuelas, a la que en este caso debemos sumar su espontaneidad. El clima que se vivió en la conversación fue agradable y muy emotivo.

La estrategia metodológica para el análisis de la entrevista es cualitativa (Kornblit, 2004), regida por la modalidad comprensiva (Bertaux, 1981; Bertaux y Wiame, 1993), que se centra en descubrir los significados que los entrevistados confieren a sus narrativas a través del análisis de los ejes temáticos que regirán la pauta y por los lineamientos del método biográfico (Arfuch, 2002). Además, se han incorporado otras nociones centrales de diversos autores, entre ellas la de "biografema", que Barthes define como: "una serie de destellos de sentido que conforman algo así como 'una historia pulverizada"” (Barthes, 1979, p. 14); vale decir que se trata de trazar una historia de vida a través de porciones de existencia, rastros y huellas dejadas por aquellos que no están.

Siguiendo a Bertaux (1981), se da asimismo relevancia a la identificación de ciertos "índices", aspectos que son reconocidos por los autores de los relatos o por los investigadores como hechos que han marcado la experiencia de vida, con respecto a los cuales se plantean en los análisis interrogantes relativos a su significación sociológica (Bertaux, 1981; Bertaux y Wiame, 1993). También en el análisis de las narrativas se adopta la noción de un "punto de viraje" o "momento bisagra", que refiere al momento vital identificado por el sujeto o por el investigador como una encrucijada a partir de la cual el itinerario biográfico de la persona toma un rumbo distinto o es el inicio de una nueva etapa (Bertaux, 1981; Bertaux y Wiame, 1993). Finalmente, y profundizando en esta senda, se hace uso de la figura de las "epifanías", tal como lo propone Denzin para referirse a experiencias que se constituyen como revelaciones, que "dejan marcas en las vidas de las personas, cuyos significados están dados siempre retrospectivamente, en la medida en que son reexaminados $a$ posteriori" (Denzin, 1989, p. 23).

Es importante señalar que, dentro de este enfoque comprensivo, tiene una relevancia especial el contexto sociohistórico en el que se desenvuelve la vida de los entrevistados, lo que implica tomar en cuenta la dimensión temporal como un aspecto fundamental para la interpretación de los datos que se desprenden del relato, tanto vinculado con las etapas de la vida, como así también los cambios sociales que ocurrieron en ese tiempo (Bertaux, 1981; Bertaux y Wiame, 1993). Ello resulta fundamental para este caso, ya que se inscribe en un momento de luchas revolucionarias y violencia política en América Latina con rasgos específicos en la Argentina, con protagonismo juvenil en diversas modalidades de militancia y acción directa (Carnovale, 2011), seguido por el terrorismo de 
Estado y la dictadura cívico-militar (1976-1982), que da lugar a vivencias generacionales y trayectorias biográficas muy marcadas por la coyuntura política. Por último, cabe recordar que una biografía -en especial narrada en primera persona - no es una representación de lo real ni una descripción objetiva de los hechos, sino más bien una permanente puesta en sentido de estos, lo cual permite construir de modo reflexivo la propia identidad e historia y las del mundo vívido en que se inscribe y hace posible.

\section{Breve historia de Carmen "Ledda" Barreiro}

Se llama Carmen Barreiro, pero siempre la llamaron "Ledda". La última dictadura cívico-militar le arrebató a su hija Silvia Graciela Muñoz, embarazada de dos meses, el 22 de diciembre de 1976; y a su yerno Gastón Andrés Larrieu, cuya fecha de desaparición es incierta. Su nieto/a debió haber nacido entre julio y agosto de 1977.

Su madre fue hija de italianos y su padre hijo de una indígena y un argentino por cuarta generación. Su papá nació en Lobos, en el 1900, venía de una familia muy humilde. A los cinco años lo llevaron a trabajar a las cosechas de maíz, siendo un niño lo prestaron como esclavo y a los doce años decidió escaparse. Se unió a los "crotos", personas que no tenían oficio ni domicilio fijo. Ellos fueron los que le enseñaron a leer y escribir. Luego trabajó en varias estancias. Se convirtió en anarquista. Tiempo más tarde, fue a trabajar a la ciudad de Mar del Plata, donde conoció a Rosa, la mamá de Ledda. El matrimonio Barreiro tuvo cuatro hijos.

Durante su juventud, Ledda conoció a quien tiempo después se convertiría en su marido, Alberto Muñoz. Se casaron y no tardaron en llegar los hijos; Silvia, Beto y doce años después, nació Fabián. Siendo adolescentes, estos ya comenzaron su trayectoria en la militancia: Silvia en la Juventud Universitaria Peronista (JUP) y Beto en la Unión de Estudiantes Secundarios (UES). Este y su mujer, Ivonne, fueron presos políticos durante la dictadura cívico-militar, Ledda y su marido también estuvieron detenidos tres meses durante esos años. Ella militaba en el Partido Auténtico. Silvia militó desde sus dieciséis años hasta fines de 1976, momento de su desaparición.

Sumada a su propia actividad política, a partir de la desaparición de Silvia, Ledda sumó a sus modalidades de lucha la búsqueda, primero de su hija, y luego la de su nieto/a, que se continúa hasta el día de hoy; y finalmente la de la justicia por las causas de las que ella misma fue protagonista como víctima del terrorismo de Estado, convirtiéndose en un testigo clave en juicios por crímenes de lesa humanidad.

\section{Análisis de la entrevista: la historia de Ledda en primera persona}

En el relato de Ledda, la militancia es parte de la vida familiar, sin distinciones de edad ni de posición de parentesco: padres e hijos en espacios políticos diferentes, sus vidas y sus vínculos cobran sentido al enlazarse en una aventura familiar que no tiene principio ni fin. Como antecedente, Ledda toma la historia de vida de su padre, que se cría con los "crotos" y se convierte en anarquista, sin que eso impida que funde una familia y lleve adelante diferentes proyectos sociales y emprendimientos comerciales, fallidos y exitosos, pero siempre con una impronta libertaria y extraordinaria.

Dentro de esa larga aventura de la que participan distintas generaciones, el período de la violencia política y la represión estatal que comienza en el 75 y llega hasta el 83 -incluyendo la desaparición de Silvia — es el más trágico, y todos los miembros de la familia -incluido su hijo menor, entonces de nueve años- sufren la prisión y la tortura. Desde entonces, la lucha nunca termina: sigue con la búsqueda de la hija desaparecida y su nieto/a (ya que estaba embarazada), la fundación de Abuelas en Mar del Plata, sus operaciones y tratamientos de afecciones graves y crónicas producidas por la tortura en su detención, la muerte del marido por inanición, la lucha por los derechos humanos, la búsqueda de justicia y su participación como testigo clave en diversos procesos judiciales contra los genocidas, que involucran la causa de su hija y la suya propia.

Se organizará la presentación de este material intentando esquematizar temporalmente el relato de Ledda pero sin pretensión de estructurarlo o cerrarlo, ya que justamente su entrevista se caracterizó por la falta de linealidad, los saltos temporales y vacilaciones, y el exceso - en muchos momentos poéticos- de sentido y sensibilidad. En este aspecto, es importante destacar que Ledda prestó poco interés a cualquier rigor cronológico al narrar sus experiencias, aunque respondió sin dificultades a nuestras preguntas en búsqueda de coordenadas precisas de tiempo y espacio; no hizo ningún esfuerzo para distanciarse emocionalmente de las duras experiencias que trajo, de hecho, en muchos pasajes de la entrevista el hilo se desvaneció a favor de su intensidad, como si la historia estallara.

La espontaneidad y la carnalidad de esta entrevista es su rasgo más notable, seguramente proviene de la modalidad singular con que Ledda ha construido y sigue construyendo su memoria, que nos refiere más a un ejercicio de anamnesis y rememoración ensoñada que a una fijación en un relato testimonial. No es la historia de Ledda la que estaba allí, como si ella pudiera leerla y narrarla para nosotras, sino que era Ledda misma la que estaba - no alli sino siempre aquí-sumergiéndose con las preguntas en un pasado que "no pasa" (Conan y Rousso, 1994). La entrevista fue en un clima distendido en el cual poco a poco se fueron desplegando fragmentos de su vida y de su familia, su militancia, su accionar en la justicia y su actual búsqueda; pero nunca en forma estructurada, siempre estableciendo cruces entre uno y otro y dejando abierta la trama. "El amor atraviesa toda mi historia" — sostiene 
Ledda—, y como parafraseando a Carver (2010) cuando dice que en el amor siempre se es principiante, se mete en su propia historia como si la descubriera por primera vez.

A continuación, se presentarán fragmentos selectos de la entrevista, organizándolos de acuerdo con tres momentos que hemos fijado esquemáticamente para su análisis. Resultan así los siguientes ejes: (a) la militancia política (1975-1983), (b) la desaparición de Silvia y su duelo (1976 en adelante), (c) el testimonio ante la justicia (2010-1012).

\section{Primer eje: la militancia política (1975-1983)}

En el relato de Ledda, la militancia aparece como algo siempre presente en su vida, enraizado en su historia familiar y en gran medida percibida como natural, como se puede apreciar en este fragmento de entrevista:

Ledda: Yo siempre pensaba... Me acuerdo cuando lo mataron al Che Guevara, la lucha de América Latina, de Nicaragua...Y yo pensaba: ¿por qué los argentinos hacen las revoluciones en las cocinas, tomando mate? Y... Debe ser por mi herencia paterna, ¿Por qué los cambios que son revolucionarios los tienen que hacer los demás? ¿Por qué tenemos que ser espectadores de lo que pasa? ¿Por qué no podemos involucrarnos en la lucha?... Entonces a mí me parecía natural que mis hijos militaran.

Es interesante notar su concepción de la condición humana como naturalmente política - al modo del zoon politikon - que no ha aprendido sino "heredado" de su padre, ella genera una interrogación crítica sobre los argentinos como expresión de una idiosincrasia nacional y un colectivo del que es parte, pero del cual se distingue. Enmarcada en un ideario con clivaje en un contexto sociohistórico particular (Bertaux, 1981; Bertaux y Wiame, 1993), Ledda inscribe su identidad y la de los argentinos en la pertenencia más amplia a América Latina, en tanto patria grande que aparece como genuina, profunda y legítima.

Es quizá esta relación natural con la política la que la coloca en la lucha armada sin cálculo personal respecto del peligro que esta implicaba. Aunque consciente de él, en el horror del terrorismo de Estado reconoce una novedad de otro orden, inesperada ("de golpe") e imprevista (lo "impensable"):

\footnotetext{
E: A pesar de haber visto el peligro, ¿vos nunca tuviste miedo?
}

L: No, porque ¿sabes qué pasa?, no había tiempo. Era como el día a día. De golpe se transformó en que te podían matar.

E: ¿Se veían venir con la dimensión que tuvo?
L: No, nunca, nadie, jamás. Pensar que la gente iba a desaparecer, era impensable.

Si la desaparición se insinúa ya como inefable como algo que "no, nunca, nadie, jamás" - se termina de componer como ominoso en el siguiente relato, sobre la primera vez que el comando parapolicial — que luego terminará por instalarse cada noche durante una larga temporada en la casa familiar situada en la zona del bosque, mientras ellos se recluyen en un departamento en el centro de la ciudad - viene a buscar a Beto, el hijo mayor de Ledda, en 1975:

L: Buscaban a Beto, porque era responsable de la UES en Mar del Plata. Vivía en casa, todavía no había empezado la masacre 6 . Llegan a casa -ellos nunca jamás mataron de día, yo les decía 'los que llegan con la noche'- y Fabián, que tenía 9 años, dormía con un cuchillo bajo la almohada, y con Alberto decidimos dejarlo y no decirle nada. La noche que llegan, no escuchamos los coches, los escucha él. Y lo recuerdo clarito porque dice 'ya llegaron'. ¡Mirá cómo los estaba esperando!

Y Beto se había ido con Silvia e Ivonne, que estaba embarazada, a la casa de mis padres en Santiago del Estero. La cuestión era saber dónde estaban. Era una patota enorme, enorme. Todos de traje y corbata, menos uno que estaba de jean. Estaban excitados, parecían perros excitados. Empezaron a buscar a buscar a buscar... No encontraron nada. Y ¿¿dónde están? ¿Dónde están?, Y ¿dónde están’? Nada... Fabián sabía dónde estaban los hermanos. Y empiezan a ponerse locos cuando no lo encuentran al 'hijo de puta', como le decían ellos. Se golpeaban el pecho y gritaban 'nosotros somos los verdaderos peronistas'. Entonces, lo agarran a Fabián. Nos obligan a mirar y empiezan a torturar a Fabián que tenía 9 años. Nos daban a elegir, 'o ese hijo o los otros dos'. A Alberto lo tenían en una punta, a mí me tenían en otra, no podíamos mirarnos, pero se ve que nos conectamos porque yo no sabía hasta cuando iba a aguantar, porque te obligaban a mirar y cuando lo tienen a Fabián entre mis piernas, lo miro e hizo un gesto como que iba a llorar. Porque mientras le hacían todo eso yo pensaba —mirá lo que pensaba yo en el horror y las ganas de gritar, porque si tenía un arma, los mataba - pensaba: 'si llora, les va a decir'. Esa conducta la contuve durante mi cautiverio, 'no hay que llorar', porque te quiebran. En un momento puedo decirle susurrando 'no llores que son unos hijos de puta'. Empieza a clarear y Fabián no dijo nada.

6 Según venía hablando, se refiere a la llamada Noche de las corbatas. Se trata del conjunto de secuestros ocurridos entre el 6 de julio y la madrugada del 13 de julio de 1977, en la ciudad de Mar del Plata. Fueron onde las víctimas en total, entre ellas varios abogados laboristas. 
En este biografema, lo ominoso hace su entrada a ese espacio de lo familiar que se volverá ajeno. Curiosamente, esperado por el hijo menor de la casa, que está en guardia y vela por todos. Es el que tiene miedo y duerme con un cuchillo bajo la almohada, y es también - por lo mismo- el más valiente, el que a los nueve años es capaz de soportar la tortura sin quebrarse: sin "llorar". Como vemos, la infancia como categoría se desvanece, Fabián es un militante más tanto para los parapoliciales como para su madre. También el cuerpo y el dolor físico son puestos fuera del relato; el quiebre que se resiste es de otro orden: emotivo y moral, hace a la dignidad del militante y de la persona. "No llorar" es un mandato para resguardarse de la autocompasión, del colapso emocional, y caer en el quiebre moral: delatar al compañero, porque aunque Beto sea el hermano, acá el cuidado no es maternal sino militante. "No llorar porque son unos hijos de puta" es mantenerse íntegro, seguir en la lucha es aguantar y "no hablar". Aun a los nueve años. Como en un cuento, el día los devuelve a la normalidad, cuando empieza "a clarear", los invasores deben irse, como si fueran fantasmas de la noche.

Esta negación de la dimensión personal, subsumida en la figura del militante compañero, no solo afecta a la vivencia inmediata de lo corporal sino también a su relato, que al igual que el dolor debe evitarse.

L: -Beto tuvo el triste privilegio de inaugurar la cárcel de Videla, en Caseros. Un día le voy a preguntar [refiriéndose a los años en los que fue un preso político], porque en nuestra familia ino hablamos de esas cosas!

El código implica dignidad para aguantar el dolor y pudor para guardar en la propia memoria el ultraje físico y la tortura. Lo que amenaza a la integridad física corporal de la persona no debe transformarse en experiencia de desintegración moral del militante; por eso, frente a la posibilidad de que un compañero se quiebre, se lo acompaña. Y aunque sea también un hijo, ni se pregunta ni se cuenta sobre lo que "le hacen", se habla de "la vida".

L: Beto militaba en la cárcel, entonces fue a parar al pabellón de la muerte. Lo íbamos a ver, porque preso político que no tenía visitas ni cartas no lo resistía, en Caseros hubo más de veinte suicidios [...]. Ni nosotros le preguntábamos qué le hacían ni él nos contaba. Nos dedicábamos esos diez minutos, quince, a veces media hora a abrazarnos y a hablar de la vida. Yo me enteraba mucho de lo que le hacían en la fila de los familiares para entrar a la cárcel (hasta tres cuadras tenía), porque no le tocaban la cabeza, le tocaban el cuerpo. Hasta que nos dice Beto, nos dice por qué no tratábamos de comunicarnos con Amnistía Internacional para garantizarle la vida. Los torturaban cotidianamente, por eso se mataban.
Y pese a que la tortura aparece como provocando la muerte, el móvil es siempre para Ledda la aniquilación moral, su quiebre; aquello de lo cual "nunca" se habla, porque se resguarda la dignidad y la integridad. La vulnerabilidad como condición humana es reemplazada aquí por una fortaleza militante que trasciende la debilidad del cuerpo, y es fundamentalmente moral, la valentía de quien, aun siendo más débil físicamente, no puede ser vencido:

E: ¿Lo torturaban para sacarle información?

L: No, no, para quebrarlo. Pura perversión.

E: Y vos con Beto ¿nunca hablaste de lo que pasó en la cárcel?

L: Nunca. No me parece que corresponda. Cada uno pasó su tortura y no vamos a intercambiar torturas.

Los vínculos familiares y la relación de parentesco quedan suspendidas, se pueden burlar - como vemos en el próximo fragmento- sus regulaciones e interdictos. La militancia permite ingresar a un espacio de lo íntimo que deja de serlo y al que se puede acceder a pesar de lo "incestuoso":

L: Hacíamos el encuentro con Silvia, y Beto sabía que hacíamos el encuentro con ella, que nos pasaba información para él a través de los que ellos llamaban "caramelo". Nunca leí un caramelo, eran sagrados porque era información de militante a militante. Con papel de arroz y cinta scotch, lo envolvían chiquitito. Yo me lo ponía en la boca... escondido, porque te hacían abrir la boca. Las requisas eran una tortura

\section{E: ¿Y cómo hacías para esconderlo?}

L: No sé... ¡El sobreviviente! El caramelo me lo daba Silvia, y cuando estaba en la cola, hacía que bostezaba y me lo ponía en la boca. Entonces eran besos incestuosos con Beto, porque nos besábamos en la boca y yo le pasaba el caramelo. Esa era la información que tenían de afuera.

\section{Segundo eje: la desaparición de Silvia y su duelo (1976 en adelante)}

Cuando se le pregunta a Ledda por la edad de sus hijos y le toca responder por Silvia ella dice:

L: No puedo decir la edad de Silvia. Aunque a ustedes les parezca mentira no hablamos entre las Madres y las Abuelas de estas cosas. Pero me imagino que a todas 
nos pasa lo mismo. Se nos congela tal cual las vimos por última vez o cuando ya eran tan jóvenes. Y se nos quedó congelada esa imagen. Entonces yo no puedo ir haciéndola crecer en mi imaginación, sí al nieto.

E: ¿Te la imaginás hoy a Silvia?

L: No

E: ¿Y qué edad tiene Silvia para vos?

L: En mi cabeza tiene siempre veintiún años. Y la escucho reír y me imagino que se va a asomar por la puerta y me va a decir "qué hay de nuevo viejo". Porque tenía esa costumbre de asomarse. Tengo ese recuerdo de ella y no la puedo hacer crecer. No me la imagino con canas, no me la imagino con arrugas. En cambio, mi nieto fue creciendo imaginario y yo creo que si lo veo en la calle lo reconozco.

E: ¿Cuántos años tiene tu nieto?

L: 38

E:-O sea... superó a Silvia.

L: Sí, sí. Yo creo que es la no aceptación del "desaparecido", el duelo no resuelto, no verla muerta... Debe tener que ver con eso.

En este fragmento del relato puede evidenciarse de algún modo que para Ledda, Silvia no murió. Ella necesita de pruebas concretas, como "verla muerta" para poder hacer el duelo. Y aquí se evidencia la ambivalencia de la figura del desaparecido, que da lugar a dos posibles interpretaciones: la muerte por un lado y la eterna presencia por el otro.

El recuerdo de Ledda inmortaliza a Silvia en un tiempo estancado, como suspendido en aquella imagen de los veintiún años donde su hija se quedó allí detenida, joven, sin canas y sin arrugas. Otra de las cosas interesantes de este fragmento es que a su nieto puede hacerlo crecer a lo largo de los años porque a él lo vincula con la vida, no así a su hija.

Cuando se le pregunta cómo era Silvia, Ledda responde:

L: Silvia era... Era... Era desopilante y a mí me hace acordar al verso de Neruda que dice "te pareces a la palabra melancolía.

Era muy linda, pero no porque era mi hija, era muy linda. Medía más de 1,70. Tenía unas piernas... Y tenía una cara preciosa. Era muy linda y graciosa. Y con el padre tenía una relación muy especial. Ella empieza a los dieciséis años la facultad [...].
Como la militancia era una manera de vivir en los 70 , era natural que todos los chicos militaran. La militancia era común.

E: ¿Ustedes estaban al tanto de su militancia?

L: ¡Si!

E: ¿Y la apoyaban?

L: ¡Si!

E: ¿Vos también eras militante?

L: Yo llegué a militar pocos meses en el Partido $\mathrm{Au}-$ téntico.

E: ¿Alberto también?

L: No, pero estaba al tanto. Les discutía... Recuerdo una discusión muy rica que hubo entre él —cuando hablo de discusión hablo de intercambio- con los compañeros de Beto... Todos los chicos de la UES iban a parar a casa y todos los chicos de la JUP que eran compañeros de Silvia también. En mi casa siempre había chicos, siempre.

Yo aprendía mucho de Silvia, ella me da alegría. Solía levantarme cuando éramos felices.... Y me quedaba mirando como dormía - Silvia, ¿eh? No los chicos, Silviay yo le decía pielcita de durazno porque tenía pielcita preciosa, piel de durazno, sentía una cosa en el estómago. Era tan sabia... que me preguntaba por qué era tan sabia con tan pocos años y me daba como miedo y me levantaba y no podía dormir... O a la mejor tenía un presentimiento, ¿no?... Ella me dejo la herencia esa: que la vida hay que vivirla si estás vivo.

Hay muchas cuestiones que destacar de este fragmento. Por empezar, los rasgos que menciona Ledda para describir a su hija están asociados, por un lado, al carácter de juventud de Silvia: desopilante, graciosa, linda, melancólica, preciosa; por el otro, remarca sus valores de militante, considerándola portadora de una sabiduría única a pesar de su juventud. También es importante mencionar que Ledda habla de Silvia en tiempo pasado, ella ya no está, no hay rastros de un presente en su narración.

Es interesante aquí destacar el rol de madre de la abuela en la escena cuando la veía dormir. Parece una anécdota, pero en verdad es una porción de su vida que opera en la construcción de la imagen de su hija y de ella misma como biografema (Barthes, 1979). Se trata de una narración que viene como a atestiguar la relación especial de madre e hija que siempre tuvieron ambas, como así también el presentimiento de que algo malo iba a sucederle. La referencia a la "pielcita de durazno" como algo inmaculado e inocente y, por sobre todas las cosas, la posición de madre 
que Ledda ocupa en esta escena, ese rol maternal que en otros fragmentos pudo verse disociado con su faceta de mujer militante dentro del núcleo familiar.

En este fragmento subyace de modo residual la idea de que la disposición a la política es cultural en aquella época (los 70). "Como la militancia era una manera de vivir en los 70, era natural que todos los chicos militaran. La militancia era común”. Lo residual (Williams, 1980) se forma en el pasado, pero todavía se encuentra en actividad como un efectivo elemento del presente. Aún hoy todos los miembros de la familia militan.

Otra de las cuestiones que aparece tanto en este fragmento como a lo largo de la entrevista, es la posición de Alberto en la familia. Él no militaba, pero sabía perfectamente la actividad de todos los miembros y a su vez los aconsejaba y hablaba con ellos de la situación que se estaba viviendo. Era una suerte de espectador de la historia.

Por último, otra de las cosas que aparece en el relato es la permanente relación entre la muerte y la militancia. Esto puede desprenderse de la enseñanza que le dejó Silvia a Ledda: "Que la vida hay que vivirla si estás vivo".

\section{Tercer eje: el testimonio ante la justicia (2010 y 2012)}

A partir de los juicios que se iniciaron en todo el país por los crímenes cometidos durante la dictadura cívico-militar, Ledda y su familia fueron convocados como testigos en la causa del Circuito Camps (2012) y ella especialmente fue una de las responsables de que se condenara con su testimonio por delitos de índole sexual durante el terrorismo de Estado al exsuboficial de la Fuerza Aérea, Gregorio Rafael Molina, por violaciones reiteradas en el centro clandestino de detención "La Cueva" (2010).

Luego de declarar en la causa del Circuito Camps, pidió permiso para decir unas palabras y le fue concedido el pedido. Respecto de ese momento ella cuenta:

L: Les dije: 'Yo los veo con el rosario, tan creyentes...Y las aberraciones más grandes las hicieron esos tipos. Y mi hija entre ellos. Pero en el juicio se saben las aberraciones que hicieron, se cuentan. Ya que son tan creyentes con el rosario en la mano y están convencidos de que van a estar a la diestra de Dios, entonces yo les voy a hacer un pedido. Ustedes saben dónde está mi nieto con quién está, saben todo, obviamente saben todo. Entonces invocando a esa creencia de que Dios está con ustedes, le digo, como todos nos vamos a morir y todos somos viejos, yo también soy vieja pero ustedes también son viejos, pero ustedes son creyentes y yo no, los invito como una simple mujer que se ha dedicado a buscar a su nieto que hagan una carta a abrirse post mortem que diga dónde están los nietos -encarecidamente les pido por el mío-y la sellen con lacra, que ustedes saben cómo es la lacra, el escribano la guarda en una caja fuerte, y a su muerte es abierta'.
Se desprenden varias cuestiones interesantes de este relato. Por empezar, ella siempre se pone en segundo lugar, siempre en un primer plano está la causa colectiva: "las aberraciones más grandes las hicieron esos tipos. Y mi hija entre ellos" y también puede notarse lo mismo cuando habla del hijo de Silvia: "que digan dónde están los nietos —encarecidamente les pido por el mío-”. Si la justicia llega para todos, también llegará para ella. No hay egoísmo en su relato, hay solidaridad.

También menciona a la religiosidad como rasgo que los diferencia, pero apela a la vejez como característica que los iguala. Ella los confronta a la verdad ante la muerte y los pone a duelo con su religiosidad.

Hay una dignidad en su discurso: les hace un pedido encarecido, no los insulta, nos los ofende, no les reclama y los mira a los ojos. Ella puede sostenerles la mirada con la dignidad de una militante. Ledda está por encima del odio porque solo pide justicia. En cuanto a lo retórico, es llamativo el fallido que comete en su relato cuando habla del lacre del sobre, confundiéndose con "lacra" que no es otra cosa que un defecto que marcan a una persona o a la sociedad.

En lo que respecta a su declaración en la causa sobre Gregorio Rafael Molina, ella cuenta:

L: Cuando se lo condenó a Molina, él era un torturador muy conocido en la Cueva, un depravado, ese me tuvo a mí [Refiriéndose a su cautiverio]. Entonces el hombre iba a salir en libertad, entonces me vienen a ver los abogados querellantes...Vienen a mi casa y me dicen 'te venimos a decir que Molina va a estar en libertad en tal fecha'. Conociéndolo a Molina, iba a estar en la esquina de mi casa, todo el tiempo. Era así Molina, un hijo de puta. Pero me dicen: 'hay una herramienta que lo haría volver a la cárcel para siempre'. ¿Cuál?, le digo yo, 'la violación'. Yo nunca hable de violación, no quería declarar, me daba vergüenza por los chicos, con Silvia no me hubiera dado vergüenza. $\mathrm{Ni}$ a Alberto se lo había contado...

Les digo, ‘¿Pero están seguros que va a quedar preso?’. 'Absolutamente.' ¿Puede ser audiencia privada?', 'sí. Hay otra mujer que estuvo en manos de él, y yo sé que le pasó lo mismo que a mí y les dije que hablen con ella y díganle que yo declaro. Y ella dijo: 'Si Ledda declara, yo declaro'. Se hace la audiencia, que era oral y pública, pero yo pedí que fuera privada. El tipo se quería morir, se quería morir. Y yo lo quería mirar a la cara y decirle ‘jtomá!' Y la otra mujer también lo hizo. Y le dieron perpetua y se convirtió en una figura jurídica internacional donde la violación bajo el terrorismo de Estado en cualquier parte del mundo es delito de lesa humanidad. El tipo se murió en una cárcel común. No lograron sacarme la ternura ni la risa. Me volví a mi casa y dormí doce horas seguidas. 
Si bien Ledda relata con fluidez los hechos de su vida, este episodio en particular parece costarle especialmente. En lo que respecta a las figuras retóricas hay una repetición del "entonces" que genera la sensación del paso lento del tiempo. Como si diera la sensación de que ese hecho fuera en otro registro de tiempo y espacio.

También el uso del "vienen" y "me vienen", como si fuera ese pasado trágico de su cautiverio el que golpea a su puerta nuevamente. No sabemos a ciencia cierta lo que sucedió con Molina durante la detención de Ledda, pero cuando ella dice "conociéndolo a Molina, iba a estar en la esquina de mi casa”, se evidencia claramente que aquella persona tiene algo personal con ella. El pasado le retorna en la imagen de Molina y no terminará el vínculo mientras él no permanezca preso. Molina la tortura en su intimi$\mathrm{dad}$, en ese mundo al que nadie ingreso hasta que tuvo la oportunidad de hacer algo para obtener justicia. Entre el pudor y la justicia, no lo dudó. Esa barrera del mundo íntimo se puede traspasar cuando el bien es mayor, como en este caso, lograr la cadena perpetua sobrepasando lo personal, sentando un precedente y convirtiéndose esta condena en ser la primera por delitos de índole sexual durante el terrorismo de Estado.

La declaración de Ledda marca claramente un antes y un después en su vida, lo que encuadraría a este acontecimiento en el orden discursivo de lo que Denzin (Kornblit, 2004) llama "epifanía". En ese sentido, el relato de Ledda es sin duda epifánico, pues su vida ya no volvió a ser la de antes, y cuando dice "no lograron sacarme la ternura ni la risa. Me volví a mi casa y dormí doce horas seguidas" La ternura parece ser algo de otro orden, es en ese momento cuando se toma consciencia de que, pese a todo, no le ganaron, solo lastimaron su cuerpo, pero no la quebraron, jamás lograron quebrarla y por eso, durmió tranquila. Aquí se ve no solo la dignidad de una militante, sino que es la dignidad de la mujer, a lo femenino que, a pesar de todo, puede seguir amando y sonriendo.

\section{Discusión y conclusiones}

La militancia como identidad, como saber corporal y como código moral atraviesa todo el relato de Ledda y vertebra los tres ejes que hemos definido para el análisis: (a) la militancia política (1975-1983); (b) la desaparición de Silvia y su duelo (1976 en adelante) y (c) el testimonio ante la justicia (2010 y 2012). La clave del análisis está ligada al carácter dinámico que atribuimos a los procesos de construcción de memorias condensados en estos ejes que, en el caso estudiado, tienen un desarrollo ininterrumpido de cuatro décadas. A lo largo de las mismas, se entretejen en la subjetividad de la entrevistada y se articulan con otros procesos intersubjetivos de construcción: institucionales y sociales.

Hemos visto a lo largo del análisis del relato de Ledda, que la militancia subsume la dimensión de lo familiar, llegando a poner en suspenso los códigos de parentesco, así como la relación entre edades y roles, que se redefinen en relación con el modelo de "compañero". Aquí la dignidad se impone como un valor ligado al no "quebrarse", a no delatar a otro militante, a resistir y "aguantar" el dolor físico a favor de una integridad moral, propia de héroes o mártires.

En este sentido y pese a la desaparición de Silvia, en el relato de Ledda no hay víctimas sino militantes que asumieron con entereza su papel y que — como cuenta con orgullo- quienes siguen vivos se mantienen activos como sujetos políticos, luchando por la memoria y la justicia.

A lo largo de la entrevista se nota que la práctica de la militancia de los 70 incorporaba la conciencia de la muerte como posibilidad, pero al mismo tiempo se sostenía en el ejercicio de una fuerte reivindicación de la vida, enfatizando el compañerismo irrenunciable y el amor. En tal sentido, la familia aparece en esta historia como lugar natural de la aventura política, y si bien los códigos de la militancia se imponen sobre los códigos familiares, la familia tiene un rol fundamental como agente de herencia - no transmisión sino herencia, en palabras de Ledda- de la política como destino. Esto se expresa en el hecho de que la historia de su padre es lo primero que ella narra, aunque le preguntáramos por los 70 creemos que es porque él es el antecedente a partir de cuya figura revolucionaria y anarquista se inscribe para Ledda toda la saga familiar posterior (de ella, de sus hijos y de los nietos).

En cuanto al dolor corporal y al duelo por la hija desaparecida, encontramos que para Ledda el plano físico queda en segundo lugar frente al moral, que se sostiene en dos valores claves: dignidad y resistencia. Aunque la desaparición de Silvia sea asumida explícitamente por Ledda como su muerte, notamos el carácter ambivalente de la figura de la hija en tanto "desaparecida" (Calveiro, 1998), que por un lado es una presencia que reclama en una búsqueda nunca acabada, y por el otro se asocia a una "eterna juventud", que suspende el tiempo.

Finalmente -y este acaso sea el rasgo más singular del relato de Ledda - se ve que compone la historia de su hija en articulación con su propia figura e historia como militante y como víctima de la tortura, luchando por causas revolucionarias primero, luego por la búsqueda de los hijos y nietos secuestrados y desaparecidos, y finalmente por la justicia. Su testimonio en los tribunales - tan difícil de llevar a cabo para ella porque implica por primera vez poner palabras sobre esa zona de la que "no se habla" (ligada a la tortura y a la violación del cuerpo) - marca también un punto de viraje en su propia biografía y se conforma como una auténtica epifanía (Denzin, 1989), que habilita el triunfo de la ternura y la risa o de lo que , en otras palabras, Bataille caracteriza como erotismo: "el triunfo de la vida aún en la muerte” (Bataille, 2007, p. 58). 
Es al cruzar esa línea, marcada por el pudor de los cuerpos sufrientes y torturados de los militantes secuestrados o presos que ella encuentra - precisamente en la vulnerabilidad - un retorno pleno a su propia vida, el cual le permite dar descanso a su dolor y rescatarse plenamente. Este momento adquiere además un impacto en el mundo con resonancia histórica en la jurisprudencia internacional, ya que a partir del testimonio de Ledda se considerará a los delitos de índole sexual aplicados en condiciones de terrorismo de Estado como delitos de lesa humanidad. Como dijera Yerushalmi (1989), el antónimo de la memoria no es el olvido, sino la justicia.

\section{Referencias}

Arfuch, L. (2002). El espacio biográfico. Dilemas de la subjetividad contemporánea. Buenos Aires: Fondo de Cultura Económica.

Anguita, E. y Caparrós, M. (2006). La voluntad. Una historia de la militancia revolucionaria en la Argentina. Buenos Aires: Booket.

Bertaux, D. (1981). Biography and Society: The Life History Approach in the Social Sciences. Londres: Sage.

Bertaux, D. y Wiame, I. (1993). Historias de vida del oficio de panadero. En J. Marinas y C. Salamanca. (Eds.). La Historia Oral: Métodos y Experiencias. Madrid: Debate.

Bataille, G. (2007). El erotismo. Buenos Aires: Tusquets.

Calveiro, P. (1998). Poder y desaparición. Los campos de concentración en Argentina. Buenos Aires: Colihue.

Calveiro, P. (2005). Politica y/o violencia. Una aproximación a la guerrilla de los años 70. Buenos Aires: Norma.

Carnovale, V. (2011). Los Combatientes. Historia del PRT-ERP. Buenos Aires: Siglo XXI Editores.

Carnovale, V. (2013). Nuestros años sesenta, cinco décadas después. Quinto Sol, 17(2).

Carnovale, V. (2014). El PRT-ERP en el exilio. Armas, comunismo y Derechos Humanos. Revista de Historia, 15.

Carnovale, V. (2015). Más allá de la militarización: la violencia revolucionaria, esperanza y promesa de emancipación Pasado Abierto. Revista del CEHis Mar del Plata, 1, 121-142.

Carver, R. (2010). Principiantes. Buenos Aires: Anagrama.
Conan, E. y Rousso, H. (1994). Un passé qui ne pase passe pas. Paris: Fayard.

Crenzel, E. (Coord.). (2010). Los Desaparecidos en la Argentina. Memorias, representaciones e ideas (1983-2008). Biblios: Buenos Aires.

Denzin, N. (1989). Interpretive Biography. Qualitative Research Method Series. Londres: Sage. https://doi.org/10.4135/9781412984584

Guglielmo, L. y Kriger, M. (2011). Memorias intergeneracionales de la Dictadura: Un estudio sobre el reconocimiento de la dimensión juvenil y de la dimensión politica de los hijos desaparecidos, en narrativas biográficas de Abuelas de Plaza de Mayo. Trabajo presentado en el IV Seminario Internacional Políticas de la Memoria. Buenos Aires, Argentina.

Guglielmo, L. y Kriger, M. (2012). La construcción del "hijo desaparecido" y su relación con las memorias emblemáticas del pasado reciente. Jornadas Internacionales de Problemas Latinoamericanos. Mendoza, Argentina.

Guglielmo, L. y Kriger, M. (2014). Un estudio sobre la relación entre las memorias sociales del pasado reciente y las memorias biográficas de mujeres integrantes de Abuelas de Plaza de Mayo y su vínculo con las significaciones que adquieren los conceptos de política y juventud de los desaparecidos a través de sus narrativas, en el contexto de los dos primeros gobiernos kirchneristas (2003-2011). REDCOM. Buenos Aires, Argentina.

Guglielmo, L y Kriger, M. (2015). El concepto de "desaparecidos" en narrativas biográficas de Abuelas de Plaza de Mayo y en las memorias emblemáticas sociales del pasado dictatorial. Trabajo presentado en VIII Seminario Internacional Memoria. Verdad. Justicia. Debates y políticas de memoria en Argentina. Buenos Aires, Argentina.

Kornblit, A. (Coord.). (2004). Metodologias cualitativas en Ciencias Sociales. Buenos Aires: Biblos.

Ollier, M (1986). El fenómeno insurreccional y la cultura política (19691973). Buenos Aires: CEAL.

Ollier, M. (2009). De la revolución a la democracia (1976-1992). Buenos Aires: Siglo XXI Editores.

Terán, O. (2006). La década del 70: la violencia de las ideas. Lucha Armada en la Argentina, 5, 20-28.

Yerushalmi, Y. (1989). Reflexiones sobre el olvido. En Y. Yerushalmi, N. Loraux, H. Mommsen, J. Milner y G. Vattimo, Usos del olvido: comunicaciones al coloquio de Royaumont. Buenos Aires: Nueva Visión.

Williams, R. (1980). Marxismo y literatura. Barcelona: Península. 